\title{
Pediatric severe asthma is characterized by eosinophilia and remodeling without $\mathrm{T}_{\mathrm{H}} 2$ cytokines
}

\author{
Cara J. Bossley, MBChB ${ }^{a, b}$, Louise Fleming, MD ${ }^{a, b}$, Atul Gupta, MBBS ${ }^{a, b}$, Nicolas \\ Regamey, MD $^{c}$, Jennifer Frith, MBBS ${ }^{a}$, Timothy Oates, BSc $^{b}$, Lemonia Tsartsali, MD ${ }^{a}$, Clare \\ M. Lloyd, $\mathbf{P h D}^{\mathrm{b}}$, Andrew Bush, $\mathbf{M D}^{\mathrm{a}}$, and Sejal Saglani, $\mathbf{M D}^{\mathrm{b}}$ \\ aRespiratory Paediatrics, the Royal Brompton and Harefield NHS Trust, Sydney Street, London \\ bLeukocyte Biology Section, National Heart \& Lung Institute, Imperial College London \\ 'Division of Paediatric Respiratory Medicine, Department of Paediatrics, Inselspital and University \\ of Bern
}

\begin{abstract}
Background-The pathology of pediatric severe therapy-resistant asthma (STRA) is little understood.

Objectives-We hypothesized that STRA in children is characterized by airway eosinophilia and mast cell inflammation and is driven by the $\mathrm{T}_{\mathrm{H}} 2$ cytokines IL-4, IL-5, and IL-13.

Methods-Sixty-nine children (mean age, 11.8 years; interquartile range, 5.6-17.3 years; patients with STRA, $n=53$; control subjects, $n=16$ ) underwent fiberoptic bronchoscopy, bronchoalveolar lavage (BAL), and endobronchial biopsy. Airway inflammation, remodeling, and BAL fluid and biopsy specimen $\mathrm{T}_{\mathrm{H}} 2$ cytokines were quantified. Children with STRA also underwent symptom assessment (Asthma Control Test), spirometry, exhaled nitric oxide and induced sputum evaluation.
\end{abstract}

\begin{abstract}
Results-Children with STRA had significantly increased BAL fluid and biopsy specimen eosinophil counts compared with those found in control subjects (BAL fluid, $P<.001$; biopsy specimen, $P<.01$ ); within the STRA group, there was marked between-patient variability in eosinophilia. Submucosal mast cell, neutrophil, and lymphocyte counts were similar in both groups. Reticular basement membrane thickness and airway smooth muscle were increased in patients with STRA compared with those found in control subjects $(P<.0001$ and $P<.001$, respectively). There was no increase in BAL fluid IL-4, IL-5, or IL-13 levels in patients with STRA compared with control subjects, and these cytokines were rarely detected in induced sputum. Biopsy IL- $5^{+}$and IL- $13^{+}$cell counts were also not higher in patients with STRA compared with those seen in control subjects. The subgroup $(n=15)$ of children with STRA with detectable $\mathrm{BAL}$ fluid $\mathrm{T}_{\mathrm{H}} 2$ cytokines had significantly lower lung function than those with undetectable BAL fluid $\mathrm{T}_{\mathrm{H}} 2$ cytokines.
\end{abstract}

Conclusions-STRA in children was characterized by remodeling and variable airway eosinophil counts. However, unlike in adults, there was no neutrophilia, and despite the wide

(C) 2012 American Academy of Allergy, Asthma \& Immunology

Corresponding author: Sejal Saglani, MD, Respiratory Paediatrics, Imperial College London, 374 Sir Alexander Fleming Building, Exhibition Road, London SW7 2AZ, United Kingdom. s.saglani@imperial.ac.uk..

Disclosure of potential conflict of interest: A. Gupta receives research support from the British Medical Association. N. Regamey is on advisory boards for Merck-Sharp and Dome and Novartis. C. M. Lloyd is a consultant for MedImmune. The rest of the authors declare that they have no relevant conflicts of interest. 
range in eosinophil counts, the $\mathrm{T}_{\mathrm{H}} 2$ mediators that are thought to drive allergic asthma were mostly absent.

\section{Keywords}

Pediatric asthma; eosinophilia; remodeling; severe therapy-resistant asthma; mediators

The 5\% of patients with asthma classified as severe consume more than $50 \%$ of health care resources for the disease. Previous pediatric studies have investigated the pathology of "difficult asthma" 1,2 after a steroid trial and also mild-to-moderate asthma, ${ }^{3,4}$ but the pathology of true severe therapy-resistant disease has been little studied. Children referred to us for evaluation of symptoms refractory to high-dose conventional asthma therapy are considered to have "problematic severe asthma." 5 This group comprises those with the wrong diagnosis, asthma with comorbidity, difficult asthma, and severe therapy-resistant asthma (STRA). They undergo detailed evaluation both at home and in the hospital. 5,6 Those with difficult asthma in whom potentially reversible factors (persistent allergen exposure, poor adherence, and poor inhaler technique) contributing to poor asthma control are identified are excluded. ${ }^{5}$ Those remaining with genuine STRA undergo invasive testing with bronchoscopy, bronchoalveolar lavage (BAL), and endobronchial biopsy to characterize airway pathology and develop an individualized treatment plan. ${ }^{7}$

Previous studies have reported submucosal eosinophilia in pediatric patients with mild-tomoderate asthma ${ }^{3,4}$ but not in children with problematic severe asthma. ${ }^{2}$ However, this included patients with difficult asthma and subjects in whom bronchoscopy was performed after a high-dose steroid trial. A further report in patients with difficult asthma has shown increased epithelial eosinophil and neutrophil counts and higher BAL levels of IFN- $\gamma$ in children with persistent symptoms compared with those with good symptom control. ${ }^{8}$ However, there was no nonasthmatic control group and no assessment of basic asthma management.

In summary, the basic mechanisms and airway pathology in children with true STRA are unknown. Adult studies suggest that in many patients the pathobiology of severe asthma is mediated by immune pathways driven by $\mathrm{T}_{\mathrm{H}} 2$-type $\mathrm{CD} 4^{+} \mathrm{T}$ cells, with signature cytokines including IL-4, IL-5, and IL-13. ${ }^{9,10}$ Hence biological modifiers of $\mathrm{T}_{\mathrm{H}} 2$-type cytokines are a rational strategy for developing new treatment approaches in adults. ${ }^{9}$ However, all studies to date, whether in vivo experimental models or in vitro models, have been conducted with adult animals ${ }^{11}$ or samples, ${ }^{12}$ respectively. Children with STRA are known to be markedly atopic, ${ }^{13,14}$ and therefore we hypothesized that these children would also have eosinophilic and mast cell inflammation and that childhood STRA would be characterized by increased levels of the $\mathrm{T}_{\mathrm{H}} 2$ cytokines IL-4, IL-5, and IL-13. The aim of this study was to characterize the pathology and mediators of inflammation and remodeling in patients with STRA.

\section{METHODS}

\section{Subjects}

Children aged 5 to 16 years referred to Royal Brompton Hospital with problematic severe asthma between April 2005 and June 2009 were included. ${ }^{6}$ Definitions of poor control and entry criteria were as follows:

1. persistent (most days for $\geq 3$ months) chronic symptoms (which prompt use of short-acting $\beta_{2}$-agonists $\geq 3$ times per week) of airway obstruction despite high doses of inhaled corticosteroids (ICSs; $\geq 800 \mu \mathrm{g} / \mathrm{d}$ budesonide equivalent) and/or 
regular oral corticosteroids, long-acting $\beta_{2}$-agonists, and current (or previous failed trial of) montelukast OR

2. recurrent severe exacerbations requiring 1 or more admission to the intensive care unit or 2 or more hospital admissions requiring intravenous medications or 2 or more courses of oral corticosteroids in the past year despite therapy for persistent symptoms as described in (1) above OR

3. at least 1 very sudden ( $\leq 6$ hours) severe attack (requiring hospitalization) without warning despite therapy for persistent symptoms, as described in (1) above.

Outpatient nurse-led assessments were performed to assess medication, dose, device and technique, atopic status, and asthma understanding. A home and school visit was undertaken to assess adherence, the environment, and any psychosocial issues. Evaluation of adherence included prescription records, accessibility of medications, and whether medications were in date and/or unwrapped; allergen sources, such as pets within the home; and environmental tobacco smoke exposure (including cotinine measurements).

After assessment, ${ }^{6}$ those reclassified as having difficult asthma ${ }^{5}$ were excluded (Fig 1). The remaining patients with STRA were further investigated. The study was approved by the local research ethics committee, and all procedures were performed after obtaining written informed parental consent and, where appropriate, child assent.

Nonasthmatic control subjects (aged 6-16 years) were either (1) undergoing a bronchoscopy to investigate upper airway symptoms and agreed to extra research samples being taken or (2) were undergoing general anesthesia for cardiac catheterization and agreed to have a research bronchoscopy at the same time. They had no history of wheeze or lower airway symptoms, and all were deemed sufficiently stable that the extra few minutes to take research samples ${ }^{15}$ were permissible, as judged by an anesthetist independent of the study. The clinical characteristics of control subjects are shown in Table E1 in this article's Online Repository at www.jacionline.org.

\section{Investigations}

All investigations were performed on the same day. None of the children had an exacerbation at the time of bronchoscopy, and at least 2 weeks were required between the last exacerbation and investigations. Details of investigations are given in the Methods section in this article's Online Repository at www.jacionline.org.

Atopic status-Atopy was defined as 1 or more positive specific IgE RAST ( $\searrow 0.34 \mathrm{kU} / \mathrm{L}$ ) or 1 or more positive skin prick test results to aeroallergens.

Symptom control-Asthma control was assessed by using the Asthma Control Test ${ }^{16,17}$; poor control was defined as a score of less than 20 of 25 (see Fig E1 in this article's Online Repository at www.jacionline.org).

Lung function-Spirometry and bronchodilator reversibility (BDR) defined as a greater than $12 \%$ change from baseline $\mathrm{FEV}_{1}$ were measured according to American Thoracic Society/European Thoracic Society guidelines. ${ }^{18,19}$

Exhaled nitric oxide-Exhaled nitric oxide measurements at a flow rate of $50 \mathrm{~mL} / \mathrm{s}$ were made with a chemiluminescence analyzer (NIOX; Aerocrine AB, Solna, Sweden) in accordance with American Thoracic Society/European Thoracic Society guidelines. ${ }^{20}$ 
Sputum induction and processing-Sputum induction was performed with $3.5 \%$ saline $\left(0.9 \%\right.$ if postbronchodilator $\mathrm{FEV}_{1}$ was $<65 \%$ of predicted value). ${ }^{21}$ Samples were processed by adding $0.1 \%$ dithiothreitol (DTT). Supernatants were stored at $-80^{\circ} \mathrm{C}$. Samples were considered adequate if $80 \%$ or fewer squamous cells and 400 or more inflammatory cells were present and distinguishable.

Bronchoscopy, BAL, and endobronchial biopsy-Bronchoscopy, BAL, and endobronchial biopsy were performed under general anesthesia, as previously described. ${ }^{22}$ BAL fluid was processed for cytology by the hospital cytopathology department. Eosinophilia was defined as greater than $1.19 \%{ }^{23}$ and neutrophilia as greater than $3.5 \% 24$ of the total cell count. Paraffin-embedded biopsy specimens were cut and stained with hematoxylin and eosin (H\&E) to assess quality and adequate morphology and also to quantify airway remodeling (reticular basement membrane [RBM] thickness ${ }^{25}$ epithelial shedding, ${ }^{4}$ and airway smooth muscle $[\mathrm{ASM}]$ mass $\left.^{26}\right)$. Evaluable sections were also stained for eosinophils (Congo red dye), neutrophils (neutrophil elastase), mast cells (mast cell tryptase), and $\mathrm{CD}_{4} 5^{+}, \mathrm{CD}^{+}$, and $\mathrm{CD} 8^{+}$cells (for more information, see the Methods section in this article's Online Repository). All sections were coded, and inflammatory cells were expressed per square millimeter of tissue. ${ }^{25}$

Induced sputum, BAL fluid, and biopsy specimen cytokine analysis-Cytokines were quantified in BAL fluid and sputum supernatants by using the Luminex multiplex bead analysis system. The premade 21-plex Luminex plate (Bio-Rad Laboratories, Hercules, Calif) was used to assay levels of IL-1 $\beta$, IL-4, IL-5, IL-8, IL-13, eotaxin, and IFN- $\gamma$. In addition, the Cytometric Bead Array (CBA Human Inflammation kit; BD Biosciences, PharMingen, San Diego, Calif) was used to quantify IL-5 and IL-13 (for more information, see the Methods section in this article's Online Repository). ${ }^{27}$ Endobronchial biopsy specimens were stained for IL- $5^{+}$and IL- $13^{+}$cells by using immunohistochemistry, and positive submucosal cells were quantified and expressed per square millimeter of tissue (for more information, see the Methods section in this article's Online Repository).

Additional investigations to exclude alternate diagnoses-All children in whom BDR could not be demonstrated or who were nonatopic underwent high-resolution computed tomographic chest scans to exclude diagnoses, such as bronchiectasis or obliterative bronchiolitis. They also underwent blood tests to exclude rheumatologic diseases and $\mathrm{pH}$ studies to exclude gastroesophageal reflux.

\section{Statistical analysis}

There are insufficient data to inform a power calculation for pediatric biopsy studies; adult studies have reported that groups of 11 to 17 are sufficient. ${ }^{25}$ The sample size for control subjects was opportunistic. Differences between groups were assessed by using the MannWhitney $U$ test. Associations were assessed with Spearman correlation. Intraobserver repeatability was measured by calculating the coefficient of variation (CV) of 3 measurements of a section made on 3 occasions at least 3 days apart. Within-subject variability was assessed based on the $\mathrm{CV}$ of counts from 3 or more biopsy specimens from the same subject. Analysis was performed with the SPSS software, version 17 (SPSS, Inc, Chicago, Ill). A $P$ value of less than .05 was considered significant for between-group comparisons, and a $P$ value of less than .01 was considered significant for correlations. 


\section{RESULTS \\ Demographics}

Of 104 patients referred with problematic severe asthma, 51 were classified as having difficult asthma (Fig 1). Fifty-three (51\%) of 104 patients with true STRA were further investigated. The clinical characteristics of subjects are shown in Table I. Forty-five (85\%) of 53 patients with STRAwere atopic compared with 7 (47\%) of 15 control subjects $(P<$. 01 ). The median baseline $\mathrm{FEV}_{1}$ in patients with STRA was $68.5 \%$ (interquartile range [IQR], $54.8 \%$ to $86.5 \%$ ) of predicted value compared with $94 \%$ (IQR, $85 \%$ to $106 \%$ ) in control subjects $(P<.0001)$.

\section{Bronchoscopic findings}

There were no complications after bronchoscopy. Findings from nonasthmatic control subjects are listed in Table E1. Positive BAL fluid bacterial cultures were present in 10 (19\%) of 53 patients with STRA, of whom 7 (70\%) of 10 also had BAL fluid neutrophilia. Positive cultures and neutrophilia were present in 2 control subjects. BAL fluid supernatants from patients with a positive bacterial culture and neutrophilia were excluded from cytokine analysis.

\section{Inflammation in BAL fluid and biopsy specimens}

Although BAL fluid and biopsy specimens were taken from all subjects, not all samples were of sufficient quality for analysis. One hundred twenty-one biopsy specimens were taken from 69 subjects, and at least 1 specimen was suitable for assessment for all subjects, except 1 control child. Three patients with STRA and 4 control subjects only had evaluable $\mathrm{H} \& \mathrm{E}-$-stained sections and therefore only had quantification of airway remodeling. The CV for intraobserver repeatability for all biopsy specimen inflammatory cells and cytokines was less than $10 \%$ (see Table E2 in this article's Online Repository at www.jacionline.org). The intraobserver repeatability for RBM thickness, epithelial shedding, and oral corticosteroid subepithelial volume fraction of ASM indexed to subepithelial tissue (Vv) smooth muscle were $4 \%, 6.4 \%$, and $11.6 \%$, respectively. The within-subject between-biopsy variability for eosinophil counts was 54\% (see Table E3 in this article's Online Repository at www.jacionline.org). However, the between-subject variation in biopsy specimen eosinophil counts for patients with STRA was $185 \%$.

BAL fluid was available in 50 of 53 patients with STRA and 14 of 16 control subjects (Fig 1). Children with STRA had significantly increased BAL fluid eosinophil counts compared with those seen in control subjects (median, $2.7 \%$ [IQR, $1 \%$ to $7.7 \%$ ] vs $0 \%$ [IQR, $0 \%$ to $0.9 \%$ ], respectively; $P<.001$ ), although there was wide variability among patients with STRA (Fig 2, A). Subepithelial mucosal eosinophil counts were significantly higher in patients with STRA than in control subjects (median, $11.2 / \mathrm{mm}^{2}$ [IQR, 0-33.7/ $\left.\mathrm{mm}^{2}\right]$ vs $0 /$ $\mathrm{mm}^{2}$ [IQR, 0-25.1/mm $\mathrm{mm}^{2}$, respectively; $P<.01$; Fig 2, B-D).

There were no group differences in BAL fluid neutrophil or lymphocyte counts, submucosal neutrophil counts, mast cell counts, and $\mathrm{CD}_{4} 5^{+}, \mathrm{CD} 4^{+}$, or $\mathrm{CD}^{+}$cell counts (Table II). Intraepithelial and smooth muscle inflammatory cells were similar between groups. No associations were found between mucosal inflammation and lung function, sex, intubation for asthma, persistent airflow limitation, gastroesophageal reflux, or serum IgE levels.

\section{BAL fluid and sputum cytokine levels}

There were no significant differences between patients with STRA and control subjects in levels of BAL fluid IL-1 $\beta$, IL-4, IL-5, IL-8, IL-13, IFN- $\gamma$, and eotaxin when measured with the Luminex multiplex assay (see Table E4 in this article's Online Repository at 
www.jacionline.org). A few children with STRA had detectable levels of BAL fluid IL-4 (n $=10)$, IL-5 $(\mathrm{n}=8)$, and IL-13 $(\mathrm{n}=8)$; however, the group median value was in the undetectable range (see Table E4). To confirm these findings, BAL fluid IL-5 and IL-13 levels were also quantified by using the Cytometric Bead Array, and again, there was no difference between patients with STRA and control subjects (see Table E4). The limits of detection for cytokines used in both assays are shown in Table E5 in this article's Online Repository at www.jacionline.org.

There was no difference in BAL fluid $\mathrm{T}_{\mathrm{H}} 2$ cytokine levels between children with persistent symptoms and those with frequent exacerbations. However, children who had any detectable BAL fluid $\mathrm{T}_{\mathrm{H}} 2$ cytokines (any of IL-4, IL-5, or IL-13) had significantly lower $\mathrm{FEV}_{1}$ and forced vital capacity (FVC) percent predicted values and greater BDR than those with undetectable $\mathrm{T}_{\mathrm{H}} 2$ cytokines (Table III).

Forty-one children underwent sputum induction, and 36 had a sufficient sample. Children with STRA, as a group, had undetectable levels of IL-4, IL-13, and IFN- $\gamma$ in sputum (see Table E4). Eight children with STRA had detectable levels of sputum IL-5 (median, 0.9 pg/ $\mathrm{mL}$ [IQR, undetectable-1.0 pg/mL]).

\section{Submucosal IL-5+ and IL-13+ cells}

Tissue expression of IL-5 and IL-13 was assessed to further support findings from the BAL fluid and sputum cytokine quantification. The intraobserver repeatability of biopsy specimen cytokine-positive cells was less than $10 \%$. The within-subject, between-specimen variability for biopsy specimen IL-5 expression was 39\%, and the between-subject variability in biopsy specimen IL-5 expression for control subjects was $69 \%$. There was a significantly higher number of IL- $5^{+}$submucosal cells in control subjects compared with numbers seen in children with STRA (median: STRA, $47.3 / \mathrm{mm}^{2}$ [IQR, 27.6-96.4/ $\mathrm{mm}^{2}$ ] vs control subjects,

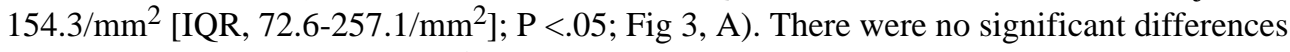
in numbers of submucosal IL-13+ cells between patients with STRA and control subjects (median, $15.95 / \mathrm{mm}^{2}$ [IQR, 9.52-34.2/ $/ \mathrm{mm}^{2}$ ] vs $8.58 / \mathrm{mm}^{2}$ [IQR, $2.08-102.3 / \mathrm{mm}^{2}$ ]), respectively (Fig 3, B).

\section{Relationship between IL-5 levels and eosinophilic inflammation}

There was no difference in biopsy specimen, BAL fluid, or sputum eosinophil counts in subjects with STRA in whom IL-5 was detected compared with counts in those in whom IL-5 was undetectable (see Fig E3). Those children in whom IL-5 was detectable in sputum had a significantly lower FEV 1 than those with absent IL-5 $(P<.05)$.

\section{Airway remodeling}

Children with STRA had increased RBM thickness compared with that seen in control subjects $(7.12 \mu \mathrm{m}$ [IQR, 6.37-7.89 $\mu \mathrm{m}$ ] vs $4.89 \mu \mathrm{m}$ [IQR, 4.16-6.16 $\mu \mathrm{m}$ ], respectively; $P<$. 0001; Fig 4, A). Epithelial shedding was similar in both groups (Fig 4, B). Vv was significantly increased in patients with STRA compared with control subjects $(0.20$ [IQR, $0-0.65$ ] vs 0.09 [IQR, 0-0.16]; $\mathrm{P}<.001$; Fig 4, ). The subepithelial volume fraction of ASM indexed to the surface area of RBM (Vs) was also increased in patients with STRA compared with that seen in control subjects (19.83 [IQR, 10.85-36.93] vs 9.14 [IQR, 4.55-15.88]; $P<.01 ;$ Fig 4, D).

\section{Influence of atopy on inflammation, remodeling, and $\mathrm{T}_{\mathrm{H}^{2}} \mathbf{2}$ cytokines}

When all subjects were compared, BAL fluid and biopsy eosinophil counts were higher in atopic compared with nonatopic subjects. RBM thickness, epithelial shedding, and ASM Vv were also greater in atopic compared with nonatopic children (Tables IV and V). However, 
atopic children with STRA had increased ASM mass compared with atopic control subjects (Tables IV and V).

\section{Influence of steroids on inflammation, remodeling, and $T_{H} \mathbf{2}$ cytokines}

There was no relationship between dose of inhaled or maintenance oral steroids and any parameters of inflammation or detection of $\mathrm{T}_{\mathrm{H}} 2$ cytokines in children with STRA (see Tables E6 and E7 in this article's Online Repository at www.jacionline.org). However, there was a negative association between ASM mass and oral steroid dose (ASM Vv: $r=-0.63, P$ $<.002$; ASM Vs: $r=-0.73, \mathrm{P}<.001)$.

\section{DISCUSSION}

In this large pediatric bronchoscopic study, an important novel facet is the use of prior detailed evaluation to exclude as far as possible all those who were nonadherent or had other confounding issues. We have shown that, unlike in adults, ${ }^{28-30}$ STRA in children is characterized by eosinophilic and not neutrophilic airway inflammation, there is no mast cell myositis, ${ }^{31}$ and the eosinophilic inflammation is not driven by signature $\mathrm{T}_{\mathrm{H}} 2$ cytokines in most patients. ${ }^{9}$

Quantification of BAL fluid cytokines was performed by using 2 separate assays, and levels of $\mathrm{T}_{\mathrm{H}} 2$ cytokines remained undetectable in patients with STRA and control subjects by using both techniques, despite the limits of detection for $\mathrm{T}_{\mathrm{H}} 2$ cytokines with both assays being low. Indeed, the assays were sensitive enough to detect the levels of cytokines found in studies of severe eosinophilic asthma, with a comparable degree of airway eosinophilia. ${ }^{32}$ In addition, induced sputum supernatants were analyzed because these are less dilute with similar results. However, our sputum samples were processed with DTT, which can affect cytokine measurements. ${ }^{33}$ Inspection of the calibration curves (see Fig E2 in this article's Online Repository at www.jacionline.org) showed that DTT did not affect IL-5 quantification but might have reduced the sensitivity for IL-4 and IL-13. DTT rendered sputum eotaxin completely undetectable. Finally, to support the BAL fluid and sputum findings, submucosal IL-5 and IL-13 expression were also quantified in biopsy specimens. Again, no differences were found in the expression of IL-13 between patients with STRA and control subjects, and if anything, $\mathrm{IL}_{-} 5^{+}$cell counts were higher in control subjects. However, the spread of data is wide (Fig $3, A$ ) and suggests the control subjects likely represent the normal range (because they include atopic subjects). We acknowledge that our control subjects were having a clinically indicated bronchoscopy and were therefore undergoing invasive procedures for significant medical problems, which might be a confounder. However, cytokine levels were predominantly undetectable in both groups, suggesting this confounder did not cause increases in false-positive results. Eight (15\%) of 53 children with STRA had detectable levels of BAL fluid and sputum IL-5; however, even in these children, there was no relationship between sputum, BAL fluid, or biopsy eosinophil counts and IL-5 levels. We therefore believe that failure to detect increased $\mathrm{T}_{\mathrm{H}} 2$ cytokine levels in our patients with STRA is real because only a very small number of children with STRA had any detectable levels in any compartment that we examined. Eight of 20 patients with STRA with BAL fluid and sputum samples had no detectable $\mathrm{T}_{\mathrm{H}} 2$ cytokines in either. None of the patients with detectable $\mathrm{T}_{\mathrm{H}} 2$ cytokines in sputum and BAL fluid had high tissue cytokine expression (defined as greater than the mean value for control subjects in biopsy specimens). Even levels of IL-5, which could be reliably quantified in BAL fluid, sputum, and biopsy specimens and is most closely related to eosinophil recruitment, were not increased.

When we split the children with STRA into those with any detectable BAL fluid $\mathrm{T}_{\mathrm{H}} 2$ cytokines (IL-4, IL-5, or IL-13) and undetectable $\mathrm{T}_{\mathrm{H}} 2$ cytokines, the former had 
significantly lower spirometric results and greater BDR (Table III), suggesting more severe disease. Looking for the presence of any $\mathrm{T}_{\mathrm{H}} 2$ cytokines in children with STRA might therefore be a biomarker that allows identification of the subgroup more likely to respond to specific antibody therapies directed against $\mathrm{T}_{\mathrm{H}} 2$ cytokines. This suggests that pediatric STRA is heterogeneous and that treatment needs to be individualized. However, when children with STRA were split according to clinical criteria into those with persistent symptoms or those with frequent exacerbations, there was no difference in $\mathrm{T}_{\mathrm{H}} 2$ cytokine levels between the 2 groups.

Another notable finding is the wide variation in BAL fluid and biopsy eosinophil counts between subjects. Although eosinophil counts were higher in children with STRA as a group compared with control subjects, within the group, eosinophil numbers were very different. This finding further underscores that STRA in children is a heterogeneous disease.

It is likely that $\mathrm{T}_{\mathrm{H}} 2$ cytokines were undetectable because these children were receiving highdose maintenance steroids. This might not have been found in previous studies because of a failure to address adherence adequately. Importantly, the samples were taken when the children were receiving their usual prescribed medication but before a high-dose systemic steroid trial, which, if given before the bronchoscopy, might otherwise have modified the airway pathology. Although some subjects were prescribed low-dose maintenance oral steroids at baseline, post hoc analysis showed no difference between the children who were and were not prescribed oral steroids and no relationships between inhaled or oral steroid dose and airway pathology. We cannot exclude the possibility that $\mathrm{T}_{\mathrm{H}} 2$ cytokines had initiated eosinophilic inflammation in patients with STRA, but we have presented clear evidence that these cytokines do not propagate established eosinophilic inflammation. We believe our data suggest that the classical $\mathrm{T}_{\mathrm{H}} 2$ cytokines IL-4, IL-5, and IL-13 are steroid sensitive and therefore undetectable and that other steroid-resistant mediators are likely responsible for driving eosinophilic inflammation in patients with severe therapy-resistant disease. Although IL-17 might be a candidate, ${ }^{34}$ the absence of neutrophilic inflammation and the fact that the source or role of IL-1 $17^{35}$ in this group is not known mean mechanisms need to be explored in experimental models ${ }^{36}$ before being confirmed in pediatric airway samples because only limited samples (both size and volume) can be obtained from children.

Our data have important practical implications. The anti-IL-5 mAb mepolizumab has been shown to be beneficial in adults with persistent airway eosinophilia and multiple asthma exacerbations. ${ }^{37-39}$ Our findings suggest that there is little indication for anti- $\mathrm{T}_{\mathrm{H}} 2 \mathrm{mAb}$ therapy in many children with STRA. In children, at least, the presence of sputum eosinophilia should not be uncritically assumed to be synonymous with $\mathrm{T}_{\mathrm{H}} 2$-driven inflammation. There is a clear need to elicit the mechanism of this apparently non- $\mathrm{T}_{\mathrm{H}} 2$ mediated airway eosinophilia to develop appropriate biological therapies in children with severe disease.

This study includes the largest cohort of children with genuine STRA that has been investigated invasively before a steroid trial. Previous pediatric reports have only included patients with difficult asthma and inflammatory data after a steroid trial. ${ }^{1,13}$ This is crucial because there is no reason to suppose a priori that airway pathology will be the same in a patients with steroid-resistant asthma as in a child who is nonadherent to ICSs.

There are a number of limitations. The study is cross-sectional, but this is inevitable because longitudinal invasive studies are unethical in children. Subjects with milder disease undergo bronchoscopy rarely, and therefore the data are only applicable to children with STRA. However, a previous study in children with mild-to-moderate asthma has shown increased tissue expression of IL-4 and IL-5, ${ }^{40}$ which is in contrast to our findings. Also, because 
control subjects were age matched and isolated upper airway problems are less common in school-aged children than those less than 5 years old, recruitment was difficult, and thus numbers were small.

Atopy was not the main focus of the study because so few of the children with STRA were nonatopic. However, increases in biopsy specimen and BAL fluid eosinophil counts, epithelial shedding, RBM thickness, and ASM mass were present in atopic compared with the very few nonatopic subjects, regardless of disease status. These findings are in contrast to a previous report in children with mild-to-moderate asthma, which showed similar pathologic changes in atopic and nonatopic subjects. ${ }^{40} \mathrm{It}$ is possible that there is an increased influence of atopy on pathology as disease severity increases. Importantly, the previous report did not include atopic nonasthmatic subjects, whereas 7 of 15 of our control subjects were atopic. When these subjects were compared with atopic patients with STRA, we found increased BAL fluid eosinophil counts, RBM thickness, and ASM mass in asthmatic patients.

In summary, we have shown that children with STRA have airway eosinophilia to varying degrees without neutrophilia or increased mast cell counts. There is considerable betweenpatient variability within this group. Importantly, signature $\mathrm{T}_{\mathrm{H}} 2$ cytokines were absent in the majority of children. This report high-lights that there might be different mechanisms driving pediatric as opposed to adult STRA and carries the implication that successful adult therapeutic strategies should not be uncritically extrapolated to children.

\section{Supplementary Material}

Refer to Web version on PubMed Central for supplementary material.

\section{Acknowledgments}

J.F. was funded by an Asthma UK Foundation Grant and a grant from the Royal Brompton \& Harefield Biomedical Research Unit. S.S. is funded by the Wellcome Trust, UK, grant no. 083586/Z/07/Z. N.R. is the recipient of a European Respiratory Society Fellowship (no. 64) and a grant of the Swiss National Science Foundation (no. $1172 / 05 b$ ). The project was supported by the NIHR Respiratory Disease Biomedical Research Unit at the Royal Brompton and Harefield NHS Foundation Trust and Imperial College London.

We thank all of the patients and parents for agreeing to take part in our study. We thank Winston Banya, statistician, for his advice, and Jackie Donovan for help with the multiplex assay. We are also grateful to our colleagues Mark Rosenthal, Ian Balfour-Lynn, Jane Davies, and Claire Hogg for allowing us to recruit their patients to this study.

\section{Abbreviations used}

$\begin{array}{ll}\text { ASM } & \text { Airway smooth muscle } \\ \text { BAL } & \text { Bronchoalveolar lavage } \\ \text { BDR } & \text { Bronchodilator reversibility } \\ \text { CV } & \text { Coefficient of variation } \\ \text { DTT } & \text { Dithiothreitol } \\ \text { H\&E } & \text { Hematoxylin and eosin } \\ \text { ICS } & \text { Inhaled corticosteroid } \\ \text { IQR } & \text { Interquartile range } \\ \text { RBM } & \text { Reticular basement membrane }\end{array}$


STRA Severe therapy-resistant asthma

Vs Subepithelial volume fraction of airway smooth muscle indexed to surface area of RBM

Vv Subepithelial volume fraction of airway smooth muscle indexed to subepithelial tissue

\section{REFERENCES}

1. Payne DN, Adcock IM, Wilson NM, Oates T, Scallan M, Bush A. Relationship between exhaled nitric oxide and mucosal eosinophilic inflammation in children with difficult asthma, after treatment with oral prednisolone. Am J Respir Crit Care Med. 2001; 164:1376-81. [PubMed: 11704581]

2. Payne DN, Qiu Y, Zhu J, Peachey L, Scallan M, Bush A, et al. Airway inflammation in children with difficult asthma: relationships with airflow limitation and persistent symptoms. Thorax. 2004; 59:862-9. [PubMed: 15454652]

3. Barbato A, Turato G, Baraldo S, Bazzan E, Calabrese F, Tura M, et al. Airway inflammation in childhood asthma. Am J Respir Crit Care Med. 2003; 168:798-803. [PubMed: 12893650]

4. Barbato A, Turato G, Baraldo S, Bazzan E, Calabrese F, Panizzolo C, et al. Epithelial damage and angiogenesis in the airways of children with asthma. Am J Respir Crit Care Med. 2006; 174:97581. [PubMed: 16917118]

5. Bush A, Hedlin G, Carlsen KH, de Benedictis F, Lodrup-Carlsen K, Wilson N. Severe childhood asthma: a common international approach? Lancet. 2008; 372:1019-21. [PubMed: 18805316]

6. Bracken M, Fleming L, Hall P, Van Stiphout N, Bossley C, Biggart E, et al. The importance of nurse-led home visits in the assessment of children with problematic asthma. Arch Dis Child. 2009; 94:780-4. [PubMed: 19546102]

7. Bush A, Saglani S. Management of severe asthma in children. Lancet. 2010; 376:814-25. [PubMed: 20816548]

8. Tillie-Leblond I, de Blic J, Jaubert F, Wallaert B, Scheinmann P, Gosset P. Airway remodeling is correlated with obstruction in children with severe asthma. Allergy. 2008; 63:533-41. [PubMed: 18394127]

9. Levine SJ, Wenzel SE. Narrative review: the role of Th2 immune pathway modulation in the treatment of severe asthma and its phenotypes. Ann Intern Med. 2010; 152:232-7. [PubMed: 20157138]

10. Slager RE, Hawkins GA, Ampleford EJ, Bowden A, Stevens LE, Morton MT, et al. IL-4 receptor alpha polymorphisms are predictors of a pharmacogenetic response to a novel IL-4/IL-13 antagonist. J Allergy Clin Immunol. 2010; 126:875-8. [PubMed: 20920778]

11. Mosmann TR, Cherwinski H, Bond MW, Giedlin MA, Coffman RL. Two types of murine helper T cell clone. I. Definition according to profiles of lymphokine activities and secreted proteins. J Immunol. 2005; 175:5-14. [PubMed: 15972624]

12. Barnes PJ. Th2 cytokines and asthma: an introduction. Respir Res. 2001; 2:64-5. [PubMed: 11686866]

13. Bossley CJ, Saglani S, Kavanagh C, Payne DN, Wilson N, Tsartsali L, et al. Corticosteroid responsiveness and clinical characteristics in childhood difficult asthma. Eur Respir J. 2009; 34:1052-9. [PubMed: 19541710]

14. Fitzpatrick AM, Gaston BM, Erzurum SC, Teague WG. Features of severe asthma in school-age children: atopy and increased exhaled nitric oxide. J Allergy Clin Immunol. 2006; 118:1218-25. [PubMed: 17157650]

15. Regamey N, Balfour-Lynn I, Rosenthal M, Hogg C, Bush A, Davies JC. Time required to obtain endobronchial biopsies in children during fiberoptic bronchoscopy. Pediatr Pulmonol. 2009; 44:76-9. [PubMed: 19085925]

16. Nathan RA, Sorkness CA, Kosinski M, Schatz M, Li JT, Marcus P, et al. Development of the asthma control test: a survey for assessing asthma control. J Allergy Clin Immunol. 2004; 113:5965. [PubMed: 14713908] 
17. Schatz M, Sorkness CA, Li JT, Marcus P, Murray JJ, Nathan RA, et al. Asthma Control Test: reliability, validity, and responsiveness in patients not previously followed by asthma specialists. $\mathrm{J}$ Allergy Clin Immunol. 2006; 117:549-56. [PubMed: 16522452]

18. Miller MR, Hankinson J, Brusasco V, Burgos F, Casaburi R, Coates A, et al. Standardisation of spirometry. Eur Respir J. 2005; 26:319-38. [PubMed: 16055882]

19. Pellegrino R, Viegi G, Brusasco V, Crapo RO, Burgos F, Casaburi R, et al. Inter-pretative strategies for lung function tests. Eur Respir J. 2005; 26:948-68. [PubMed: 16264058]

20. ATS/ERS recommendations for standardized procedures for the online and offline measurement of exhaled lower respiratory nitric oxide and nasal nitric oxide, 2005. Am J Respir Crit Care Med. 2005; 171:912-30. [PubMed: 15817806]

21. Lex C, Payne DN, Zacharasiewicz A, Li AM, Wilson NM, Hansel TT, et al. Sputum induction in children with difficult asthma: safety, feasibility, and inflammatory cell pattern. Pediatr Pulmonol. 2005; 39:318-24. [PubMed: 15678506]

22. Payne D, McKenzie SA, Stacey S, Misra D, Haxby E, Bush A. Safety and ethics of bronchoscopy and endobronchial biopsy in difficult asthma. Arch Dis Child. 2001; 84:423-6. [PubMed: 11316690]

23. Fitch PS, Brown V, Schock BC, Taylor R, Ennis M, Shields MD. Chronic cough in children: bronchoalveolar lavage findings. Eur Respir J. 2000; 16:1109-14. [PubMed: 11292114]

24. Ferreira FA, Filho LV, Rodrigues JC, Bush A, Haslam PL. Comparison of atopic and nonatopic children with chronic cough: bronchoalveolar lavage cell profile. Pediatr Pulmonol. 2007; 42:85763. [PubMed: 17726706]

25. Sullivan P, Stephens D, Ansari T, Costello J, Jeffery P. Variation in the measurements of basement membrane thickness and inflammatory cell number in bronchial biopsies. Eur Respir J. 1998; 12:811-5. [PubMed: 9817150]

26. Regamey N, Ochs M, Hilliard TN, Muhlfeld C, Cornish N, Fleming L, et al. Increased airway smooth muscle mass in children with asthma, cystic fibrosis, and non-cystic fibrosis bronchiectasis. Am J Respir Crit Care Med. 2008; 177:837-43. [PubMed: 18218992]

27. Collins DP, Luebering BJ, Shaut DM. T-lymphocyte functionality assessed by analysis of cytokine receptor expression, intracellular cytokine expression, and femto-molar detection of cytokine secretion by quantitative flow cytometry. Cytometry. 1998; 33:249-55. [PubMed: 9773887]

28. Shaw DE, Berry MA, Hargadon B, McKenna S, Shelley MJ, Green RH, et al. Association between neutrophilic airway inflammation and airflow limitation in adults with asthma. Chest. 2007; 132:1871-5. [PubMed: 17925424]

29. Simpson JL, Powell H, Boyle MJ, Scott RJ, Gibson PG. Clarithromycin targets neutrophilic airway inflammation in refractory asthma. Am J Respir Crit Care Med. 2008; 177:148-55. [PubMed: 17947611]

30. Wenzel S. Severe asthma in adults. Am J Respir Crit Care Med. 2005; 172:149-60. [PubMed: 15849323]

31. Brightling CE, Bradding P, Symon FA, Holgate ST, Wardlaw AJ, Pavord ID. Mast-cell infiltration of airway smooth muscle in asthma. N Engl J Med. 2002; 346:1699-705. [PubMed: 12037149]

32. Kaminska M, Foley S, Maghni K, Storness-Bliss C, Coxson H, Ghezzo H, et al. Airway remodeling in subjects with severe asthma with or without chronic persistent airflow obstruction. J Allergy Clin Immunol. 2009; 124:45-51. [PubMed: 19481790]

33. Woolhouse IS, Bayley DL, Stockley RA. Effect of sputum processing with dithiothreitol on the detection of inflammatory mediators in chronic bronchitis and bronchiectasis. Thorax. 2002; 57:667-71. [PubMed: 12149524]

34. Hansbro PM, Kaiko GE, Foster PS. Cytokine/anti-cytokine therapy—novel treatments for asthma? Br J Pharmacol. 2011; 163:81-95. [PubMed: 21232048]

35. McAleer JP, Kolls JK. Mechanisms controlling Th17 cytokine expression and host defense. J Leukoc Biol. 2011; 90:263-70. [PubMed: 21486905]

36. Saglani S, Mathie SA, Gregory LG, Bell MJ, Bush A, Lloyd CM. Pathophysiological features of asthma develop in parallel in house dust mite-exposed neonatal mice. Am J Respir Cell Mol Biol. 2009; 41:281-9. [PubMed: 19151316] 
37. Antoniu SA. Mepolizumab for difficult-to-control asthma with persistent sputum eosinophilia. Expert Opin Investig Drugs. 2009; 18:869-71.

38. Haldar P, Brightling CE, Hargadon B, Gupta S, Monteiro W, Sousa A, et al. Mepolizumab and exacerbations of refractory eosinophilic asthma. N Engl J Med. 2009; 360:973-84. [PubMed: 19264686]

39. Nair P, Pizzichini MM, Kjarsgaard M, Inman MD, Efthimiadis A, Pizzichini E, et al. Mepolizumab for prednisone-dependent asthma with sputum eosinophilia. N Engl J Med. 2009; 360:985-93. [PubMed: 19264687]

40. Turato G, Barbato A, Baraldo S, Zanin ME, Bazzan E, Lokar-Oliani K, et al. Nonatopic children with multitrigger wheezing have airway pathology comparable to atopic asthma. Am J Respir Crit Care Med. 2008; 178:476-82. [PubMed: 18511700] 


\section{Key messages}

- Pediatric STRA is characterized by airway eosinophilia and remodeling but an absence of the classical $\mathrm{T}_{\mathrm{H}} 2$ cytokines thought to drive allergic asthma.

- There was no neutrophilia or increase in mast cell inflammation in children with STRA, unlike in adults.

- A small subgroup of children with STRA had detectable $\mathrm{T}_{\mathrm{H}} 2$ cytokines, suggesting phenotypic heterogeneity in this group.

- Treatments, such as anti-IL-5 antibody, might be ineffective in many children with STRA, and alternative mediators driving the disease need to be sought. 


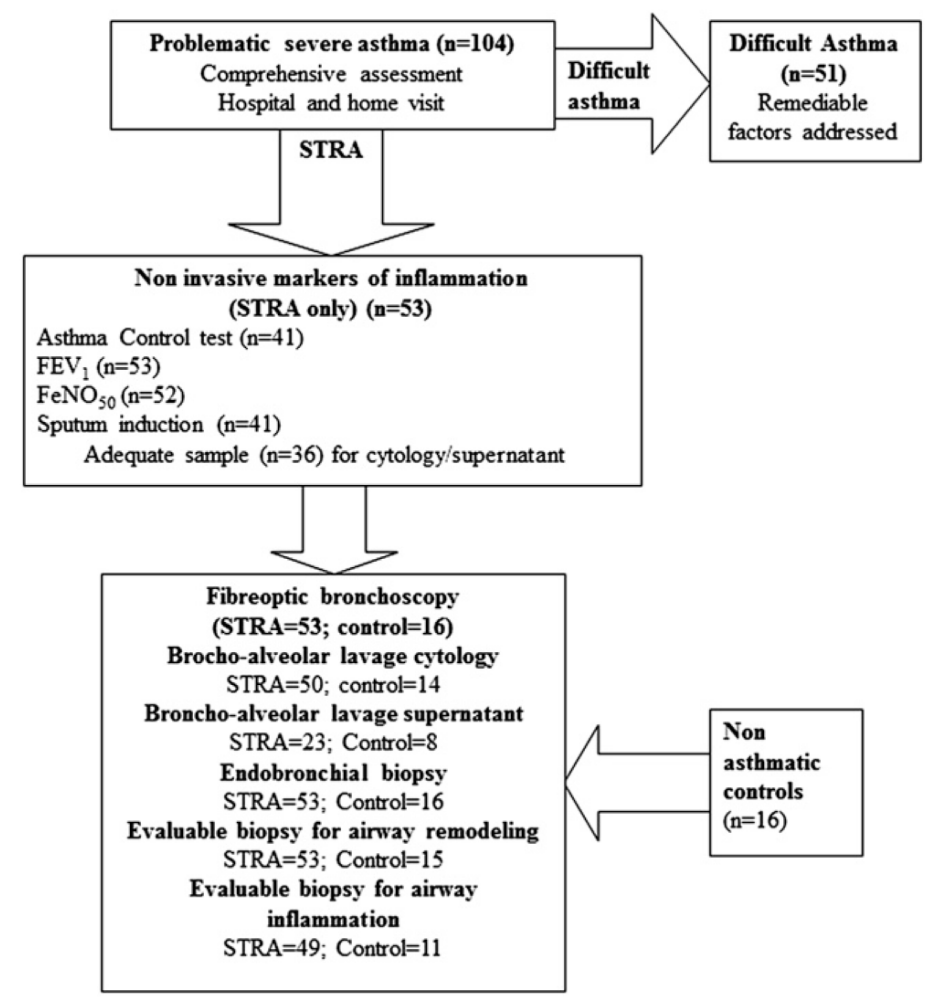

FIG 1.

Flow diagram illustrating the number of children with problematic severe asthma who were assessed and how many patients with STRA underwent invasive investigations to assess airway pathology. $F_{E N O 50}$, Fraction of exhaled nitric oxide at $50 \mathrm{~mL} / \mathrm{s}$. 
A
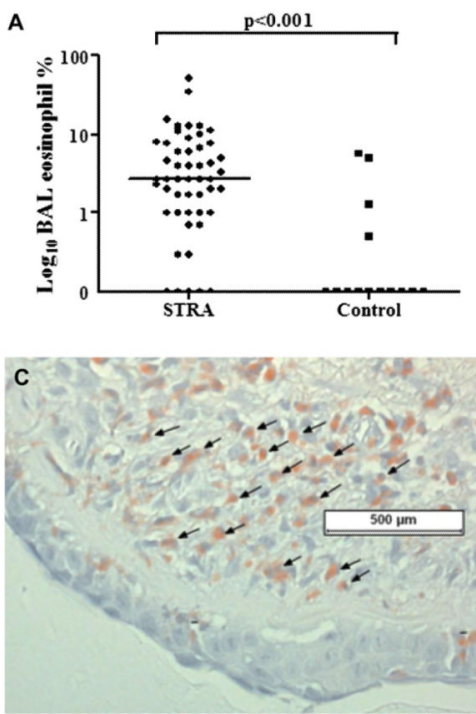
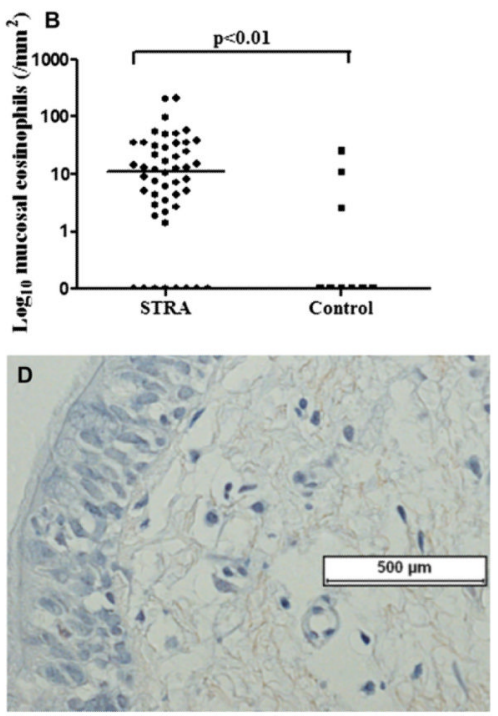

FIG 2.

$\mathbf{A}$ and $\mathbf{B}$, Increased BAL fluid eosinophil (Fig 2, A) and submucosal eosinophil (Fig 2, B) counts in children with STRA compared with those seen in control subjects. C, A 5- $\mu \mathrm{m}$ paraffin section stained with Congo red dye showing positively stained eosinophils (black arrows) in the submucosa of a patient with STRA compared with an absence of submucosal eosinophils in a control subject $(\mathbf{D}$; original magnification $\times 400)$. 

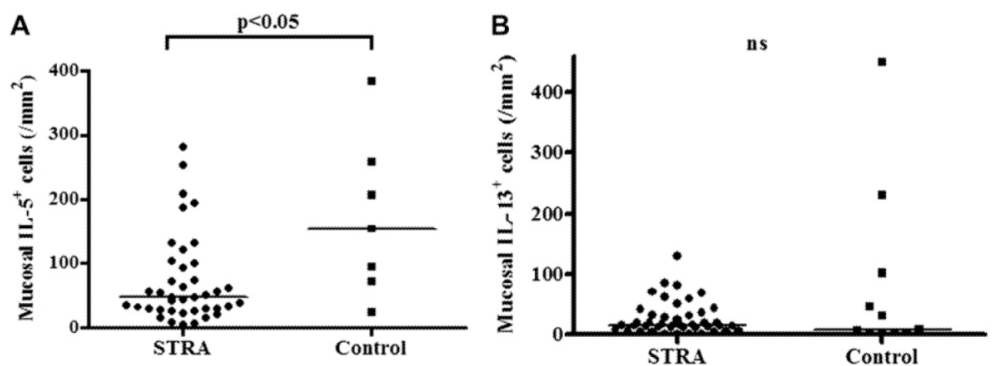

FIG 3.

Submucosal IL-5 ${ }^{+}(\mathbf{A})$ and IL-13 ${ }^{+}$(B) cell counts in biopsy specimens from children with STRA compared with control subjects. Submucosal IL- $5^{+}$cell counts were higher in control subjects compared with those seen in patients with STRA, and levels of IL-13+ cells were similar in both groups. Analyses were performed with the Mann-Whitney $U$ test. ns, Not significant. 
A
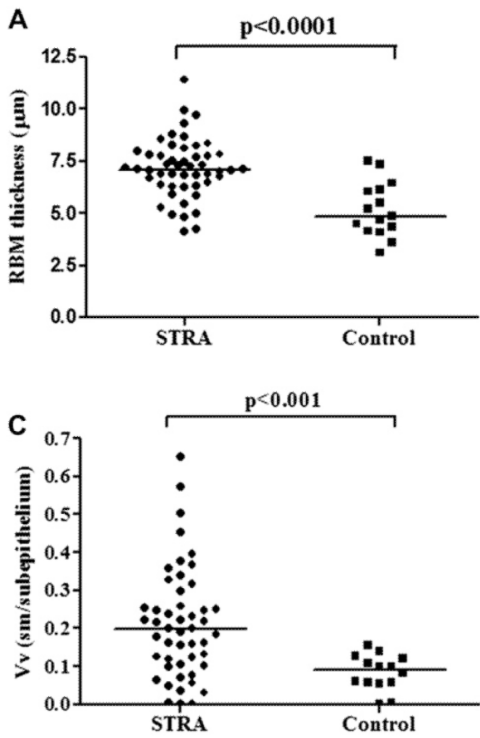

B
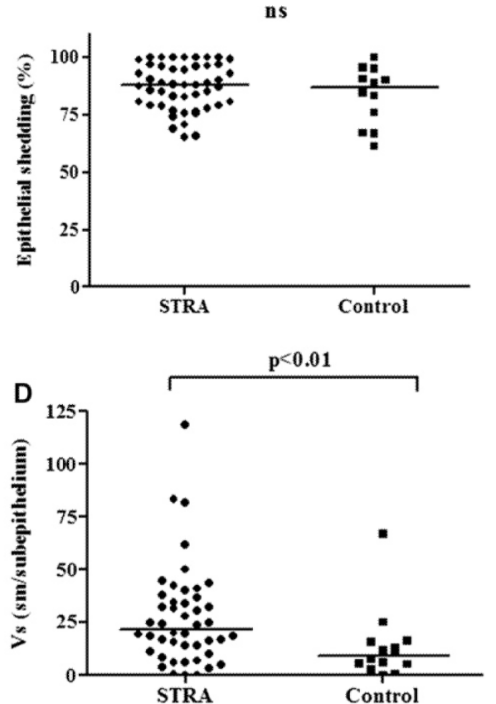

FIG 4.

Markers of airway remodeling showing increased RBM thickness in patients with STRA compared with control subjects (A), similar epithelial shedding in patients with STRA and control subjects (B), increased volume of ASM indexed to subepithelium in patients with STRA compared with control subjects $(\mathbf{C})$, and increased volume of ASM indexed to RBM in patients with STRA compared with control subjects (D). $n s$, Not significant. 


\section{TABLE I}

Clinical characteristics of children with STRA and nonasthmatic control subjects

\begin{tabular}{|c|c|c|}
\hline & $\begin{array}{l}\text { Children with STRA } \\
\qquad(\mathrm{n}=53)\end{array}$ & $\begin{array}{l}\text { Control subjects } \\
\qquad(\mathrm{n}=16)\end{array}$ \\
\hline Age $(y)$ & $11.97(9.97-14.4)$ & $10.65(7.54-12.96)$ \\
\hline Male sex & $33 / 53(62 \%)$ & $8 / 16(50 \%)$ \\
\hline Atopy & $45 / 53(85 \%)$ & $7 / 15(47 \%)^{*}$ \\
\hline Age at first symptoms (y) & $1(0.25-2.25)$ & - \\
\hline Duration of symptoms (y) & $10.1(8.3-12.7)$ & - \\
\hline Previous intubation for asthma & $11 / 53(21 \%)$ & - \\
\hline Parental smoking & $13 / 53(25 \%)$ & $2 / 9(22 \%)$ \\
\hline Percent predicted $\mathrm{FEV}_{1}$ & $68.5(54.8-86.5)$ & $94(85-106)^{\dagger}$ \\
\hline $\operatorname{BDR}(\%)$ & $15.6(5.5-23.4)$ & $2.5(0-8.5)$ \\
\hline Persistent airflow limitation & $13 / 53(25 \%)$ & - \\
\hline Total IgE (IU/mL) & $386(115-1286)$ & $40(14-130)$ \\
\hline \multicolumn{3}{|l|}{ Medications } \\
\hline $\mathrm{ICS}(\mathrm{mg} / \mathrm{d})^{t}$ & $1.6(0.8-1.6)$ & - \\
\hline Maintenance oral prednisolone & $24 / 53(45 \%)$ & - \\
\hline Long-acting $\beta$-agonist & $53 / 53(100 \%)$ & - \\
\hline Leukotriene receptor antagonist & $31 / 53(58 \%)$ & - \\
\hline Theophylline & $12 / 53(23 \%)$ & - \\
\hline ACT score $(/ 25)$ & $13(9-17)$ & - \\
\hline FENO $_{50}(\mathrm{ppb} ;$ normal, <24 ppb) & $50.3(29.3-69.7)$ & - \\
\hline $\begin{array}{l}\text { Sputum eosinophils ( } \% \text {; normal, } \\
<2.5 \% \text { ) }\end{array}$ & $7.5(3.2-30.4)$ & - \\
\hline
\end{tabular}

Values are presented as medians (IQRs).

$A C T$, Asthma Control Test; $F_{E N O 50}$, fraction of exhaled nitric oxide at a flow rate of $50 \mathrm{~mL} / \mathrm{s}$.

${ }^{*}<<.01$.

${ }^{\dagger} P<.05$

${ }^{*}$ Budesonide equivalent dose. 
TABLE II

Airway inflammation in children with STRA compared with nonasthmatic control subjects

\begin{tabular}{lccc}
\hline Cell count & $\begin{array}{c}\text { Patients with } \\
\text { STRA }(\mathbf{n}=\mathbf{5 3})\end{array}$ & $\begin{array}{c}\text { Control subjects } \\
(\mathbf{n}=\mathbf{1 6})\end{array}$ & $\begin{array}{c}\text { P } \\
\text { value }\end{array}$ \\
\hline $\begin{array}{l}\text { BAL fluid neutrophils }(\%) \\
\begin{array}{l}\text { Biopsy specimen } \\
\text { neutrophils }\left(/ \mathrm{mm}^{2}\right)\end{array}\end{array}$ & $3.5(2-7.2)$ & $2.7(1.2-7.5)$ & .37 \\
$\begin{array}{l}\text { Biopsy specimen mast } \\
\text { cells }\left(/ \mathrm{mm}^{2}\right)\end{array}$ & $45.7(25.2-69.6)$ & $60.5(45.1-76.4)$ & .20 \\
$\begin{array}{l}\text { Biopsy specimen CD45 } \\
\text { cells }\left(/ \mathrm{mm}^{2}\right)\end{array}$ & $149(3.7-419.9)$ & $209.7(168.8-244)$ & .11 \\
$\begin{array}{l}\text { Biopsy specimen CD8 } \\
\text { cells }\left(/ \mathrm{mm}^{2}\right)\end{array}$ & $51(17.9-80.5)$ & $54.8(10.1-116.8)$ & .60 \\
$\begin{array}{l}\text { Biopsy specimen CD4 } \\
\text { cells }\left(/ \mathrm{mm}^{2}\right)\end{array}$ & $145.4(77.0-224.5)$ & $176.5(23.5-259)$ & .92 \\
$\begin{array}{l}\text { Biopsy specimen CD4/ } \\
\text { CD8 ratio }\end{array}$ & $3.30(1.77-5.89)$ & $2.97(1.86-12.43)$ & .93 \\
\hline
\end{tabular}

Values are presented as medians (IQRs). 


\section{TABLE III}

Clinical characteristics of children with STRA with any detectable BAL fluid $\mathrm{T}_{\mathrm{H}} 2$ cytokines (IL-4, IL-5, or IL-13) compared with those without detectable $\mathrm{T}_{\mathrm{H}} 2$ cytokines

\begin{tabular}{|c|c|c|c|}
\hline & $\begin{array}{l}\text { Detectable BAL } \\
\mathbf{T}_{\mathbf{H}} 2 \text { cytokines } \\
\quad(n=15)\end{array}$ & $\begin{array}{c}\text { No detectable BAL } \\
\mathbf{T}_{\mathbf{H}} 2 \text { cytokines } \\
(\mathbf{n}=8)\end{array}$ & $\begin{array}{c}P \\
\text { value }\end{array}$ \\
\hline Age (y) & $11.2(9.4-14.4)$ & $11.7(10.0-12.3)$ & .78 \\
\hline \multicolumn{4}{|l|}{ Steroid dose: } \\
\hline Maintenance (mg/d) & $6.25(5.0-7.5)$ & $5.6(5.0-7.2)$ & .80 \\
\hline ICS & $1.6(1.2-1.6)$ & $1.4(0.9-1.6)$ & .27 \\
\hline Exacerbations (in past year) & $8(4-8.5)$ & $5(4-10)$ & 1.0 \\
\hline Admissions in past year & $1.5(0-5)$ & $0(0-10)$ & .70 \\
\hline Percent predicted $\mathrm{FEV}_{1}$ & $65(42.5-71)$ & $91.5(83.5-96.8)$ & $<.001$ \\
\hline Percent predicted FVC & $90(61-99)$ & $106(94.5-110)$ & .03 \\
\hline BDR (\%) & $19(14-33)$ & $8.1(3.6-17.4)$ & .03 \\
\hline ACT score (/25) & $10(8-17)$ & $13.5(8-16.5)$ & .47 \\
\hline BMI $\left(\mathrm{kg} / \mathrm{m}^{2}\right)$ & $17.6(16.1-18.6)$ & $23.8(21-28)$ & .009 \\
\hline BMI percentile & $66(22-78)$ & $99(96-99.7)$ & .005 \\
\hline
\end{tabular}

Values are presented as medians (IQRs). Boldface text indicates statistically significant results. $A C T$, Asthma Control Test; $B M I$, body mass index; $F V C$, forced vital capacity. 


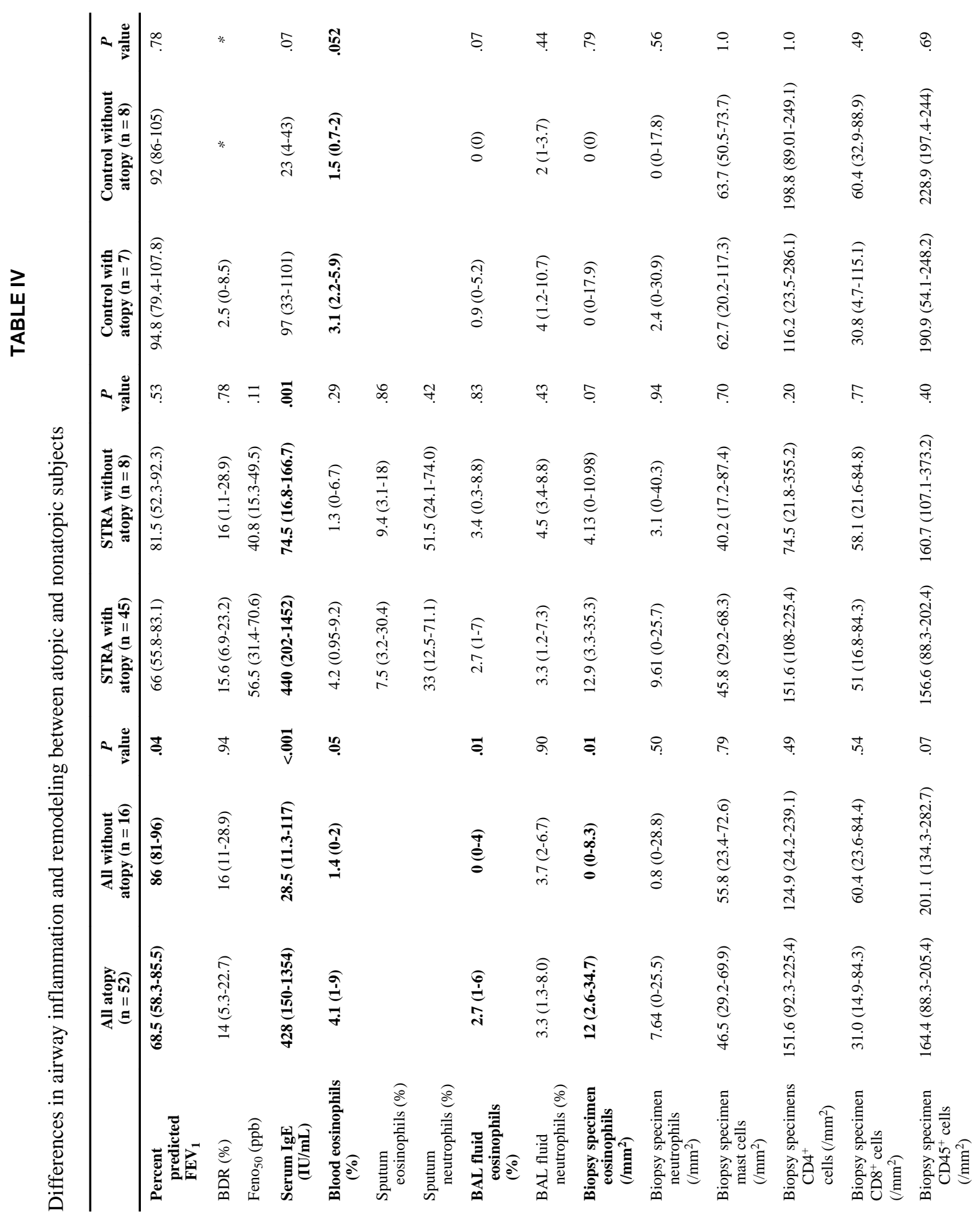




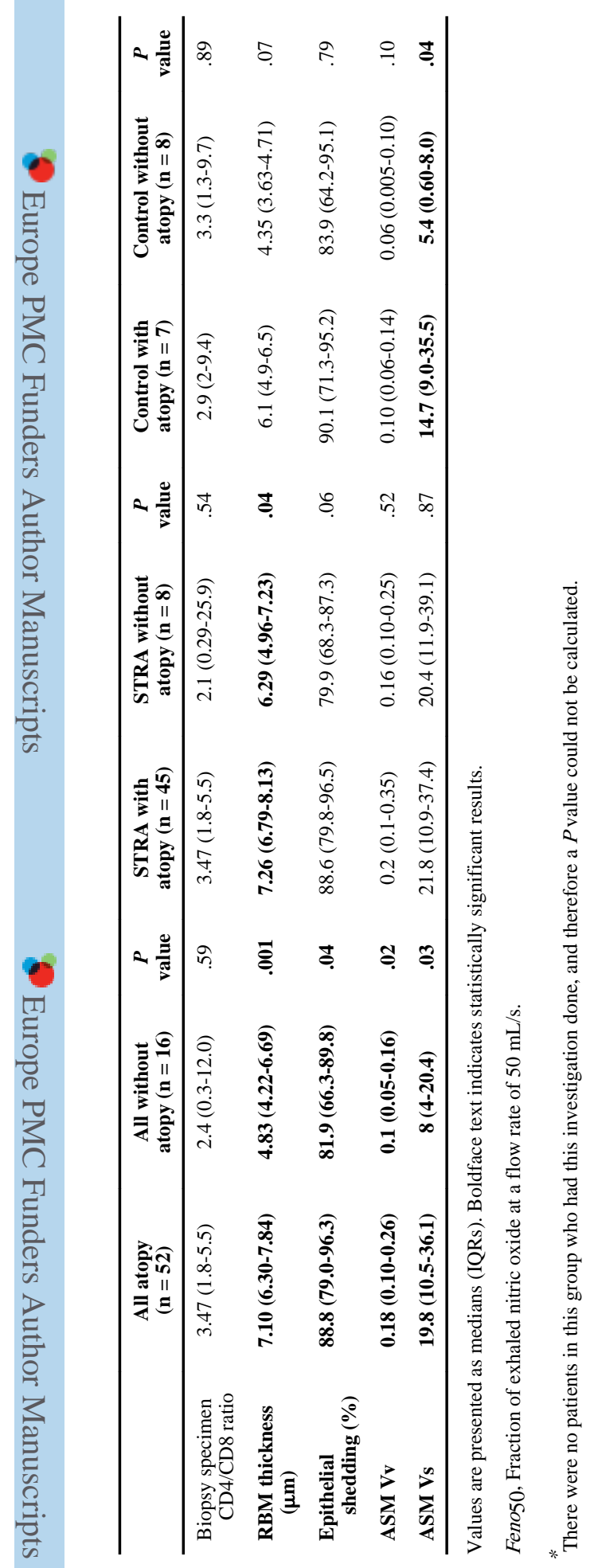




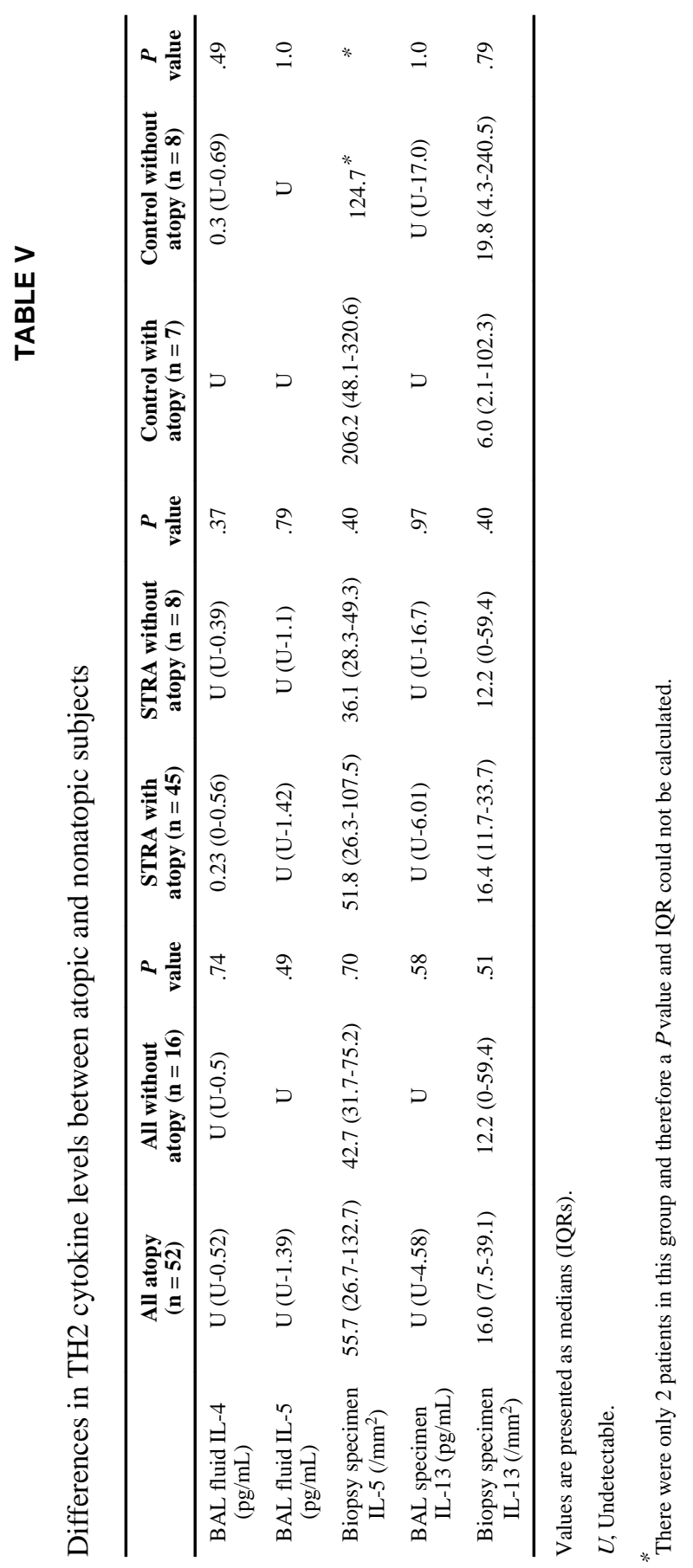

